\title{
Preface: Groundwater in Sub-Saharan Africa
}

\author{
Yongxin $\mathrm{Xu}^{1} \cdot$ Paul Seward $^{2} \cdot$ Cheikh Gaye $^{3} \cdot$ Lixiang Lin $^{4} \cdot$ Daniel O. Olago $^{5}$ \\ Received: 26 March 2019 / Accepted: 12 April 2019 / Published online: 27 April 2019 \\ (C) Springer-Verlag GmbH Germany, part of Springer Nature 2019
}

Keywords Sub-Saharan Africa · Water supply · Groundwater management · Groundwater development

\section{Introduction}

Sub-Saharan Africa (SSA; Fig. 1) refers to an area encompassing the countries in Africa that are fully, or partially, located south of the Sahara. The remaining African countries are generally referred to as belonging in North Africa. Although the socio-economic and hydrogeological conditions in SSA are diverse, they are sufficiently distinct (in general) from the conditions in North Africa to warrant being assessed separatelyfor example, high-yielding, high-storage, sedimentary aquifers are more common in North Africa than in SSA, while lowyielding, low-storage, basement aquifers are more widespread in SSA than in North Africa. The use of fossil groundwater is more typical in North Africa, while the use or renewable groundwater is more typical in SSA. Other hydrological characteristics associated with SSA include: groundwater resources that are generally under-utilized; lack of research and development that often prevents the optimal use of groundwater rather than over-development; and a heavy reliance by the rural and urban poor on shallow unconfined or semi-confined groundwater for potable water supplies, other domestic uses, and subsistence agriculture. Because of distinguishing characteristics such as these, there are good reasons for treating the hydrogeology of SSA as a whole, and separate from North Africa.

When compared with global groundwater research, groundwater research in SSA has been relatively limited, and much of this research has been driven by overseas organizations. There

Yongxin $\mathrm{Xu}$

yxu@uwc.ac.za

1 University of the Western Cape, Bellville, Cape Town, South Africa

2 Simonstown, South Africa

3 Département de Géologie, Université Cheikh Anta Diop, Dakar, Senegal

4 Council for Geoscience, Pretoria, South Africa

5 Department of Geology, University of Nairobi, Nairobi, Kenya is thus a very strong need for more attention to be given to SSA hydrogeology, and for more attention to be given to SSA hydrogeology as viewed by hydrogeologists from SSA.

The general, abstract need for more attention to be given to SSA hydrogeology by hydrogeologists from SSA was, however, not initially translated into a concrete plan for a Hydrogeology Journal special issue on SSA. Instead the initial plan was to address Africa as a whole. The idea for a Hydrogeology Journal special issue on groundwater in Africa stemmed from a discussion among Jimmy Jiao (a former Hydrogeology Journal editor), Yongxin Xu (the UNESCO Chair in Hydrogeology), and the late Phil Hobbs (a South African hydrogeologist) at the 2015 ChinAfrica Water Forum Resources Dialogue, held at the University of the Western Cape, in South Africa. The objective of the ChinAfrica Forum is a lasting partnership between China and Africa on the issue of the sustainable development of water resources in developing countries. Both China and Africa face massive challenges of human development in a changing environment, and face many similar water research, development, and implementation issues, especially in the field of groundwater. Because of the distinctive needs and characteristics of SSA, the Africa special issue morphed into the SSA special issue. The aim of the special issue is to provide hydrogeological 'snap-shots' that, when taken together, characterize current groundwater research, development, and management in SSA from the perspective of hydrogeologists from SSA. Broader issues, common to both SSA and North Africa such as long-term water level behaviour, can be found in other Hydrogeology Journal issues.

The total water resources available in the world are estimated to be in the order of $46,000 \mathrm{~km}^{3} /$ year, including about $36,000 \mathrm{~km}^{3} /$ year of surface water and $10,000 \mathrm{~km}^{3} /$ year of groundwater (Trenberth et al. 2007). These resources are distributed throughout the world according to the patchwork influences of climate and physiographic structures. At the continental level, the Americas have the largest share of the world's total freshwater resources with $45 \%$, followed by Asia with $28 \%$, Europe with $15.5 \%$ and Africa with $9 \%$. In terms of 
Fig. 1 Map showing SubSaharan Africa

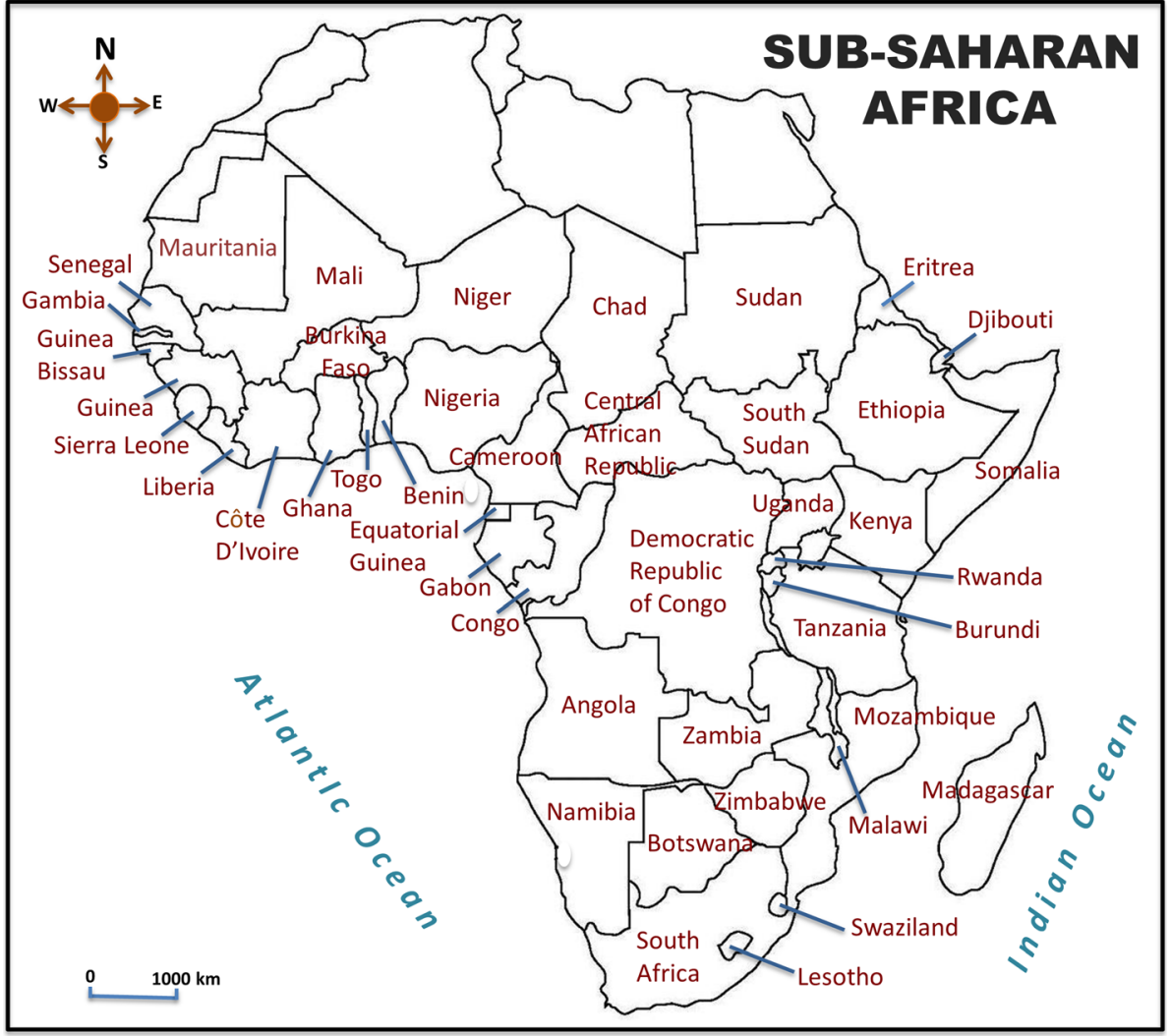

resources per inhabitant for each continent, the Americas have $24,000 \mathrm{~m}^{3} /$ year, Europe has $9,300 \mathrm{~m}^{3} /$ year, Africa has 5,000 $\mathrm{m}^{3} /$ year, and Asia has $3,400 \mathrm{~m}^{3} /$ year (FAO 2003).

MacDonald et al. (2012) produced the first quantitative maps of groundwater resources for Africa as a whole. These maps provide an indication of the magnitude and distribution of freshwater stored as groundwater. The volume of groundwater was estimated to be 0.66 million $\mathrm{km}^{3}$ for Africa as a whole, more than 100 times the annual renewable freshwater resources and 20 times the freshwater stored in African lakes. These figures seem very high, and are at odds with local experience and expertise.

The maps demonstrate the uneven distribution of groundwater across the continent and, in particular, the large groundwater volumes available in the sedimentary basins of North Africa. MacDonald et al. (2012) do not provide a storage estimate specifically for SSA; however, their estimates of groundwater storage per country indicate that groundwater storage is typically one to two magnitudes higher in North Africa than in SSA. The potential for boreholes yielding greater than $5 \mathrm{~L} / \mathrm{s}$ outside of large sedimentary basins is not widespread but limited to particular areas requiring careful exploration and development. Nevertheless, for many SSA countries, appropriately sited and constructed boreholes can support a hand pump (a yield of $0.1-0.3 \mathrm{~L} / \mathrm{s}$ ), and sufficient storage is available to sustain abstraction through inter-annual variations in recharge (MacDonald et al. 2012).
In SSA, the majority of the population are dependent on groundwater for domestic supplies, and three-quarters of all the groundwater pumped from boreholes or taken from springs is used for domestic supply. Groundwater use for irrigation is forecast to increase substantially to combat growing food insecurity on the continent. In some areas, groundwater wells are the only available drinking water source. They supply nearly all those who do not have mains water. Groundwater is also used for bottling and food processing as well as in other industrial activities. There are advantages in using groundwater for both public and private supplies, compared to surface water, as it is of relatively high quality and usually requires less treatment prior to use, even for drinking and other potable purposes (Environmental Agency 2011).

The high socio-economic and ecological importance of groundwater and its importance as a strategic resource are recognized throughout SSA; however, data on groundwater systems are sparse and the current state of knowledge is low. This is a serious limitation to the sustainable development of groundwater resources; therefore, efforts to improve the situation have been made over the last decade through the publication of syntheses and reviews at the national, regional, and continental levels.

Braune and $\mathrm{Xu}$ (2010) concluded from their work that, in contrast to its strategic role as an essential resource to help achieve community development and poverty alleviation in the Southern African Development Community (SADC), groundwater has remained a poorly understood and managed 
resource. A key finding of this scoping study regarding the status of groundwater resources management in the SADC region was that groundwater management links to groundwaterdependent sectors like agriculture, rural development, health, and environment are not well established in policy or in practice.

The GW·MATE (2011) report provides an overview of the major groundwater issues in SSA, with an assessment of policy implications in terms of potential development and appropriate management. The GW.MATE report pointed out the fact that groundwater is the preferred source to meet most water-supply demands, despite hydrogeological complexity, natural constraints on water-well yields and quality, and institutional weaknesses. The report also concluded that many countries need to undertake a strategic assessment of their groundwater and prioritize investment on institutional strengthening in order to facilitate appropriately managed groundwater development to meet the challenge of improving their urban water-supply security and to expand their irrigated agriculture. Above all, without effective use of available groundwater resources, improved livelihoods and climatechange adaptation will prove much more difficult to achieve.

Pavelic et al. (2012), in a review of the groundwater availability and use for 15 countries in SSA, confirmed the relative abundance of groundwater resources in this part of the world and provides information to consolidate the existing knowledge on groundwater use and, to a certain point, some tools to support reasonable groundwater development and governance. They concluded that groundwater is a critically important resource for human survival and economic development across the vast drought-prone areas of southern, eastern and western SSA; however, the quantitative information on aquifer characteristics, groundwater recharge rates, flow regimes, quality controls, and use is still rather patchy.

In 2012, the African Ministers' Council on Water published a status report on the application of integrated approaches to water resources management in Africa (AMCOW 2012). In particular, the report indicated great promise for water and food security in Africa, as well as for reducing the vulnerability of many countries and their populations to climate variability and change. Major challenges still abound, particularly in mobilizing the investment required to meet the targets of the Africa Water Vision 2025 for basic water supply and sanitation; irrigated agriculture; and supporting institutional development, capacity building, research, education, and information management. The report recommended that programmes be developed or strengthened for: (1) forecasting and early warning of waterrelated disasters; (2) addressing climate change adaptation through water resources management, as well as enhancing disaster risk management and water storage capacity; (3) learning through experience and country-to-country knowledge sharing; (4) assuring transparency and efficiency in water allocation and use; (5) defining the general principles, categorization, and prioritization of water uses; (6) defining water quality objectives; and (7) sustainable funding. Also, developing appropriate tools and indicators for measuring the contribution of water to development is particularly important to provide a basis for highlighting the pivotal role of water resources as an essential ingredient in the emergence of a green economy in Africa.

Despite the importance of small-scale farming in SSA, there is little information on the present and potential role of groundwater in agriculture. Widespread contamination of groundwater resources is occurring, and the important environmental services of groundwater are neglected. There appear to be critical shortcomings in the organizational framework and the building of institutional capacity for groundwater. Addressing this challenge will require a much clearer understanding and articulation of the role of groundwater's contribution to national and regional development objectives and an integrated management framework, with top-down facilitation of local actions.

There is, therefore, a need for sustainable management of groundwater resources in SSA, which requires institutional coordination and stakeholder participation frameworks, information management programs, and capacity building programs. These include (1) groundwater monitoring systems for better understanding of the role of groundwater storage and groundwater discharges in sustaining aquatic ecosystems; (2) groundwater assessments for understanding the interactions between various aquifers (including transboundary aquifers) and assessing the impact of increased pumping from various aquifer systems on the sustainability of groundwater abstraction. The ongoing groundwater-related initiatives in SSA, in the form of institutional coordination and stakeholder participation frameworks, and information management programs and capacity building programs, provide opportunities for sustainable groundwater management in SSA.

\section{Main issues}

Three main issues can be identified regarding groundwater resources in SSA and are discussed in the following subsections.

\section{Water supply and security}

This remains a high priority on a subcontinent where the UN's Sustainable Development Goals (SDGs), and in particular Goal 6 "Clean water and Sanitation", aim to carry forward the 'unfinished business' of the Millennium Development Goals (MDGs) for the provision of access to safe drinking water and sanitation that remains skewed towards urban areas (UN 2015).

Subthemes of this main theme are floods, droughts, and trans-boundary considerations and, in the longer-term, climate change. Mitigation measures include artificial recharge 
(including managed aquifer recharge and storage), watersensitive urban design, low impact development, and rainfall harvesting.

\section{Environmental resilience of aquifers}

This theme explores the capacity of groundwater systems to absorb and resist impacts and demonstrates resilience (or lack thereof) in their recovery in much the same manner as ecosystem functioning. This capacity has specific relevance to groundwater resources under threat from densely populated informal settlements and extractive industries such as mining.

Subthemes of this main theme are identified as sanitation (including bacteriological and emerging contaminants), acid rock (mine) drainage, development of a shale gas industry, and extraction of coalbed methane, etc.

\section{Regulatory setting}

The development of policy in regard to water resource management is an evolving field and aspects of governance and reform are central to this theme. The theme extends to institutional capacity to implement water governance especially within the context of a changing hydrophysical environment. Attention to this aspect is crucial to the successful attainment of goals in all other facets of the water sector. Review of policies and water laws may form an important element of the theme where and if necessary.

\section{Summary of articles}

Although the aim of this special issue was to provide a comprehensive overview of important groundwater topics in SSA, it was not possible to cover every topic outlined in the 'Introduction'. The collection of articles in this special issue should therefore be seen as an introduction to these topics rather than providing a comprehensive overview. Readers are strongly encouraged to use the articles as a basis for further exploration of these topics.

The dichotomy between governance solutions and technological solutions is explored by Olivier and $\mathbf{X u}$ in their essay on Cape Town's (South Africa) drought and water-supply crisis of 2015-2017. Their essay investigates the impact of water governance on this phenomenon. While an unprecedented sequence of three record-low rainfall years triggered the 'water crisis', the severity of the crisis may have been mitigated by good governance. It was concluded that governance failures increased Cape Town's vulnerability to a water crisis: namely mismanagement of existing surface-water infrastructure, as well as the failure to diversify water supply by utilizing existing groundwater sources, water recycling, and desalination. The lessons learned from this case could contribute to climate-change resilience planning in other SSA cities.

Water storage assessment is an important component of feasibility studies for prospective mining areas. Lin H. and Lin L. present a simplified method to assess the groundwater storage in a typical mine area-Tugela in South Africa. Two storage types are proposed, i.e. exploitable and sustainable storages. Geological, hydrogeological, and borehole information are used to estimate the groundwater storage quantity based on aquifer types and proposed mining boundaries. Recharge is also estimated and uses empirical recharge rates to compare recharge amounts with the storage amount. The assessment method can be applied to other areas with similar hydrogeological settings, provided datasets are available.

Aquifer sustainable yield is a critical parameter in studying groundwater sustainability. The determination of the sustainable yield has been of importance in managing the water resources in arid- and semi-arid regions of southern Africa. In these regions, the amount of water from borehole abstraction tests is used to provide a recommended yield. However, this yield is fixed and is not easily translated into a non-fixed sustainable yield. Lin $\mathbf{L}$. and Lin $\mathbf{H}$. therefore applied a 3D FEFLOW model to a fault-controlled aquifer in Table Mountain Group sandstones. The modelling process started with an understanding of the aquifer setting and the establishment of a conceptual model, with data derived from borehole drillings, field measurements, and hydraulic tests. Groundwater modelling was performed with the aim of determining the sustainable yield of the unconfined aquifer via flow simulation at different pumping rates. The relationship between stabilized groundwater levels and pumping rates was established, and provides a basis for determining the sustainable yield of groundwater.

Sustainable groundwater use in arid and hyper-arid areas of SSA is a key issue and is constrained, in part, by lack of resources and data. Matengu et al. present the hydrogeological characteristics of the Omaruru River Delta Aquifer (Omdel Aquifer) in the Namib Desert, focusing on groundwater recharge and discharge, groundwater dynamics within the aquifer, and groundwater chemistry to determine whether current abstraction is within the hydrogeological limits of sustainability. Sustainability is of concern because the aquifer supplies water to several domestic and industrial consumers in the Central Namib area. Up to 174 boreholes have been drilled, of which 42 are production wells; some of production boreholes have become saline. The alluvial aquifer storage is augmented by an artificial recharge scheme. There is no direct recharge from rainfall, but the aquifer does receive significant recharge from river flood pulses. The aquifer comprises four palaeochannels, of which only one provides potable groundwater. The aquifer materials range from gravels to sands, and display a wide range of transmissivities (from low to high). The groundwater is characterized spatially by a 
highly varied hydrochemistry, with seven hydrochemical facies identified. The influence of proximity to the coast is reflected in all of the facies by the presence of $\mathrm{NaCl}$. The evidence obtained indicates that over-abstraction is taking place, and the Omdel Aquifer needs to be carefully operated to ensure it remains a reliable and sustainable water resource.

Recent exploration has revealed that deep-seated and large groundwater reservoirs in Africa's intracontinental basins can be regarded as an additional strategic resource for the supply of drinking water. The origin, genesis, and recharge of these groundwater reservoirs, however, are still poorly understood. Bäumle et al. use a multi-disciplinary approach involving remote sensing, geophysical surveys, and hydraulic, hydrochemical, and isotope investigations to gain a better insight of the genesis and the potential of a recently discovered lower Kalahari aquifer (LKA) located in the Eastern Zambezi Region (Namibia). The study shows that regional tectonic activity associated with the propagation of the Okavango Rift Zone had a major impact on the drainage evolution and hydrogeological setting of the region. Furthermore, there is geomorphological evidence that the LKA - prior to tectonic subsidence and burial - was part of a paleochannel of the Upper Zambezi River. Hydraulic continuity could be confirmed by geochemical evolution down the flow path. Ion exchange combined with dissolution of calcite progressively produces alkalinity and sodium, and consumes calcium, in the $\mathrm{N}-\mathrm{S}$ direction. A comparison of stable isotope contents of the LKA with modern rainfall indicates that the recharge occurred under cooler climatic conditions when the vegetation was probably dominated by grassland. An analysis of $\mathrm{C}$ concentrations and $\mathrm{Cl} / \mathrm{Cl}$ ratios show that the age of the groundwater exceeds $100 \mathrm{ka}$ and is, hence, older than expected. It is concluded that the assessment of sedimentology, tectonic structures, and geochemistry are key factors for understanding both the paleoclimate and modern recharge processes of deep-seated aquifer systems.

Groundwater resource evaluation is a critical aspect in the development of groundwater for water supplies to various sectors and for varied uses. Crystalline basement aquifers are widespread in SSA and are associated with the Mozambique belt system.

Muchingami et al. present a review of how different methodologies are applied in the evaluation of groundwater occurrence and yield evaluation of basement aquifer formations found in the Zimbabwean hydrogeological setting. They note that aquifers in such formations tend to be associated with significant borehole failure rates and widely variable yields, yet these aquifers are critical for water supplies in many of SSA's semi-arid areas, which tend to be occupied by people in the low-income bracket. In Zimbabwe, the aquifers are mostly developed within the weathered overburden and fractured bedrock; the latter has a fracture density that decreases with depth and controls most of the aquifers' hydraulic parameters. The authors note that when selecting borehole sites, the weathering and fracture density aspects should be well studied within the context of an area's relief, geology, surface-water hydrology, soil, and vegetation cover. When selecting borehole sites, geoelectrical methods are found to be suitable for mapping the thickness and extent of the overburden, and locating and characterizing potential water-bearing structures. Furthermore, the incorporation of remote sensing and geographic information system (GIS) techniques to bring together and analyse the varied factors that influence groundwater occurrence in basement aquifers has proved to be very useful in aiding the identification of aquiferous zones. The authors conclude that improvements in the understanding of these relationships, including the susceptibility to pollution, are fundamental to the planning and management of groundwater resources in crystalline basement terrain and will contribute to the reduction of development costs. They also note that an integrated water resources management approach can help to protect vulnerable aquifers from pollution related to anthropogenic activities.

In arid and semi-arid areas, assessment of groundwater recharge is a key challenge in determining the sustainable yield of aquifers, and the recharge estimates obtained are often subject to debate and disputes. Difficulties in determining recharge rates arise because (1) the recharge rates are generally much lower than average annual rainfall or evapotranspiration and are thus difficult to determine precisely, and (2) different connotations of the recharge concept are used by surface water and groundwater groups. In southern Africa, experience of recharge estimation covers a time span of at least four decades. This experience forms the basis of a review by $\mathbf{X u}$ and Beekman, which incorporates emerging and grey literature from a wide range of research sectors in southern Africa. Their review includes the chloride mass balance $(\mathrm{CMB})$, rainfall infiltration breakthrough (RIB), Extended model for Aquifer Recharge and moisture Transport through unsaturated Hardrock (EARTH), water-table fluctuation (WTF), water balance in the saturated zone -including equal volume spring flow (EVSF) and saturated volume fluctuation (SVF) — and groundwater modelling (GM) methods. Their review shows that the methods based on mass balance and relationships between rainfall, water-level fluctuations and abstraction have a high potential for simulating and forecasting groundwater recharge, and that the EVSF and CMB methods are highly recommended for use in the southern Africa region. A South African case study indicated that caution is needed regarding the uncertainty associated with error inputs and propagation for all the methods. The review provides an updated source of references related to recharge estimation in arid and semi-arid regions of SSA, in general, and for the implementation of resource directed measures (RDM; part of the National Water Resources Strategy) in South Africa, in particular. Future work should focus on quantifying the time lag between rainfall events and water level responses, on episodic recharge, and on forecasting in the context of climate change. The decades of work on recharge assessment in the region should be collated, synthesized, and translated into userfriendly products such as manuals, databases, decision support 
systems, and analysis programs, to better serve groundwater practitioners and water managers in properly and effectively using the results. This would facilitate addressing issues such as water-sensitive urban design (WSUD) and managed aquifer recharge (MAR), which are receiving increasing attention in southern Africa.

Dolomite aquifers are the largest water source in the northern part of South Africa. Xiao et al. provide insights on the recharge zones and the dynamics of the recharge to this aquifer system using geochemical and isotopic data from water samples collected from springs. The low Na content, as well as the stable isotope ratios, suggest a present-day recharge through the infiltration of rainfall. Groundwater mean residence time (MRT) and its temporal and spatial distributions of the young dolomite spring system were analysed using an improved lumped-parameter model based on the time series of ${ }^{14} \mathrm{C}$-DIC, initial ${ }^{14} \mathrm{C}$ activities, and $\delta^{13} \mathrm{C}$-DIC of the spring samples. The results of ${ }^{14} \mathrm{C}$ dating show that the groundwater MRTs range from $\leq 10$ years to 51 years. During the sampling period (between the 1970s and 2000s), the groundwater MRTs in nine selected springs were fairly stable. Gradual increases in the groundwater MRTs of the other five springs are assumed to correspond to climate changes, especially rainfall variability. At most of the spring sites, the groundwater MRTs and hydrochemical evolution show a down-gradient trend along the flow direction. One exception was found for the Kuruman sites where the groundwater MRTs and the $\left[\mathrm{Ca}^{2+}\right] /\left[\mathrm{Mg}^{2+}\right]$ ratio gradually increased along the flow direction. This suggests that Kuruman spring flow originates from a deep groundwater resource. The article provides hydrologists with an additional method of radiocarbon dating in young dolomite aquifers, and the results would be useful for the sustainable management of dolomite aquifers in South Africa.

Groundwater research carried out in SSA is not just to advance local knowledge, but also global knowledge. Ebrahim et al. developed an integrated hydrogeological modelling approach for hard-rock aquifers in semi-arid, data-scarce areas using remote sensing, rainfall-runoff modelling, and a threedimensional (3D) dynamic model. Their integrated modelling approach was tested in the Hout catchment, Limpopo Province, South Africa, whereby the Hout catchment is an important agricultural region. Groundwater abstraction for irrigation in this region doubled during 1968-1986. An integrated dynamic 3D hydrogeological flow model was developed using the OneWater Hydrologic Flow Model (MODFLOW-OWHM) to improve understanding of recharge and flow processes, and water use and management. The results indicate a delicate humannatural system reliant on small and highly variable recharge, propagating through variable pumping to an even more variable storage, making the combined system vulnerable to climate and anthropogenic changes. The modelling developed is fundamental to the understanding of the spatio-temporal variability of the key parameters required for managing groundwater resources sustainably, and would be a useful tool in semi-arid, datascarce areas globally.

Water flow is required for the health and integrity of any wetland environment. Based on a field investigation, flow simulation, and hydrogeological data, Nonterah et al. developed a conceptual flow model representing the physical characteristics of the Sakumo wetland, Ghana. Two major groundwater flow systems were identified: local (top soil-water) flow in the alluvium and an intermediate flow in the shallow unconfined unit. A simple two-dimensional (2D) finite-difference numerical model using MODFLOW and ModelMuse was applied to analyse the groundwater flow system in the Sakumo wetland catchment. The purpose of the model was to explain the groundwater flow system, and to quantify the water fluxes contributing to the wetland water storage. The source of groundwater in the catchment is mostly from a shallow unconfined aquifer situated in the Quaternary sediment. The modelling results indicate that changes in recharge significantly affect the wetland water balance. The water table declines during the dry season because of high evapotranspiration with little rain. The modelling results confirmed that the Sakumo wetland water fluxes are predominately local to intermediate flows. The simulation of the calibrated model showed no hydraulic link between the wetland and the underlying aquifer. This study thus provides valuable hydrogeological information of the Sakumo wetland basin and lays the foundation for the development of detailed future predictive models.

Groundwater quantity and quality may be affected by climate change through complex direct and indirect mechanisms. At the same time, population growth and rapid urbanization have made groundwater an increasingly important source of water for multiple uses, both globally, and in southern Africa. A study by McGill et al. investigates the coupled human and natural system (CHANS) linking climate, sanitation, and groundwater quality in Ramotswa, a rapidly growing peri-urban area in semi-arid south-eastern Botswana. Ramotswa relies on the transboundary Ramotswa aquifer for its water supply. An analysis of long-term rainfall records indicated that droughts, such as the one from 2013 to 2016, are increasing in likelihood in the area because of climate change. Key informant interviews showed that, because of the drought, people increasingly use pit latrines rather than flush toilets. Nitrate, fecal coliforms, and caffeine analyses of Ramotswa groundwater revealed that human waste leaching from pit latrines is the likely source of nitrate pollution. The results indicate critical indirect linkages between climate change, sanitation, groundwater quality, and water security in the area. Improved sanitation, groundwater protection and remediation, and local water treatment would enhance reliable access to water, de-couple the community from reliance on surface water and associated water shortage risks, and help prevent transboundary tension over the shared aquifer.

Determining the best compromise between the benefits of groundwater use and problems caused by groundwater use is 
primarily a governance challenge rather than a technical issue. However, groundwater governance research is still in its infancy compared with the physical science aspects of hydrogeology, and there is a lack of systematic, nonanecdotal data on groundwater governance research. SSA in general, and South Africa in particular, are no exception to this rule, whereby despite having introduced very forward-thinking water legislation, the groundwater governance situation in South Africa is poor. Seward and $\mathbf{X u}$ therefore used the institutional landscape in South Africa to investigate whether the Ostrom Design Principles can be used to address the groundwater governance research gap, and to improve the implementation of groundwater governance. The principles relate to self-organizing governance systems of commonpool resources, which are more likely to be sustainable if all eight design principles - clear resource and user boundaries, collective-choice arrangements, monitoring, sanctions, and conflict-resolution mechanisms - are present. Empirical studies have proven the relevance and effectiveness of the Ostrom Design Principles for a range of common-pool resources; however, the application of the design principles to groundwater has been limited. The results of the investigation revealed that there is a very good case for making more use of the Ostrom Design Principles in groundwater governance research and implementation.

Based on a five-town case-study cohort in Kenya, Olago developed a conceptual framework to enable the formulation of holistic and effective strategies that encompass the national aspirations and regional to global sustainability agendas, and which can be used to monitor progress in achieving set objectives. The approach is flexible, scalable, and transferrable, so that it can be applied in different contexts and using different indicators, based upon the same construct. Insufficient technical knowledge of urban aquifers and their interplay with the wider social-ecological system constrains the development of holistic, effective, and robust management systems for ensuring their sustainability. The objective of the study was to consider governance and management solutions that could promote water security for urban towns in Kenya through the sustainable use of groundwater in the context of its complex hydrogeology, water access disparities, competing uses, and future risks. The national and county water policies, strategies, and plans for the case study areas were critically reviewed. The status of aquifer knowledge, water access disparities, competing uses, and risks were evaluated from critical literature reviews and data compilation, fieldwork, and analysis of indicator datasets from the Kenya 2009 census. Key aquifers need urgent characterization to reverse the tendency of development to proceed with insufficient aquifer knowledge. Private sector and public participation in management should be enhanced through decentralized management approaches. Water infrastructure and technologies should be fit-for-purpose in application and scale, and the pro-poor focus should be underpinned by appropriately focused management regimes.
Groundwater is becoming an increasingly important water resource for city, town, and rural water supplies in SSA. Mengistu et al. note that Ethiopia has seen unprecedented economic growth, averaging $10 \%$ in the last decade, which has dramatically increased the rate of urbanization. The country is also implementing large-scale irrigation projects with a strong reliance on groundwater at a level that is unprecedented in the nation's history. The authors note that these developments are being undertaken despite insufficient capacity in human resources, equipment, and management tools, thus putting at risk the sustainable development of the groundwater resources. In addition, the authors provide a high-level overview of the hydrogeological, socio-economic, and policy context of the groundwater resources in Ethiopia as a whole, outline the current state of the resource development, and discuss some of the major water quality issues with respect to fluoride, nitrogen, and microbial contamination. From their assessment, they conclude that robust water resource protection and management measures need to be put in place, and that local communities along with other stakeholders should be engaged in the planning and implementation of water resource development.

Urban groundwater in SSA provides vital freshwater to rapidly growing cities. Groundwater from Dakar's Thiaroye Aquifer (Senegal) provided nearly half of the city's water supply into the 1980s. The groundwater occurs in Quaternary unconsolidated sands. Rising nitrate concentrations caused by faecal contamination sharply curtailed groundwater withdrawals, which now contribute just 5\% to Dakar's water supply. To understand the attenuation capacity of this urban aquifer under a monsoonal semi-arid climate, Faye et al. used stable-isotope ratios of $\mathrm{O}$ and $\mathrm{H}$, and radioactive tritium $\left({ }^{3} \mathrm{H}\right)$, compiled over several studies, together with piezometric data to trace the origin of groundwater recharge and groundwater flowpaths. Shallow groundwater is derived predominantly from modern rainfall (tritium $>2$ TU in $85 \%$ of sampled wells). Values of $\delta^{18} \mathrm{O}$ and $\delta^{2} \mathrm{H}$ in groundwater vary by $>4$ and $20 \%$, respectively, reflecting substantial variability in evaporative enrichment prior to recharge. These signatures in groundwater regress to a value on the local meteoric water line that is depleted in heavy isotopes relative to the weighted-mean average composition of local rainfall. This bias suggests that recharge is preferentially derived from isotopically depleted rainfall occurring during the latter part of the monsoon (September). The distribution of tritium in groundwater is consistent with groundwater flowpaths to seasonal lakes and wetlands, as defined by piezometric records. Piezometric data further confirm the diffuse nature and seasonality of rain-fed recharge. The conceptual understanding of groundwater recharge and flow provides a context to evaluate attenuation of diffuse but effectively constant anthropogenic recharge from the vast network of sanitation facilities that drain to this aquifer.

Groundwater management decisions require robust methods that allow accurate predictive modelling of pollutant 
occurrences. Ouedraogo et al. used random forest regression (RFR) for modelling groundwater nitrate contamination at the African continent scale. Although data were data from Africa as whole, the results are particularly relevant to SSA because of its groundwater knowledge and management issue constraints. When compared with more conventional techniques, the key advantages of RFR were noted to be its nonparametric nature, its high predictive accuracy, and its capability to determine variable importance. The latter characteristic can be used to better understand the individual role and the combined effect of explanatory variables in a predictive model. In the absence of a systematic groundwater monitoring program at the African continent scale, the study used the groundwater nitrate contamination database for the continent obtained from a meta-analysis to test the modelling approach. A total of 250 groundwater nitrate pollution studies from the African continent were compiled from the literature. A GIS database of 13 spatial attributes was established. The spatial attributes are related to land use, soil type, hydrogeology, topography, climatology, type of region, and nitrogen fertilizer application rate. The attributes were used as pollution predictors. The RFR performance was compared with multiple linear regression (MLR) method results. By using RFR, it was possible to establish which explanatory variables influence the occurrence of nitrate pollution in groundwater (population density, rainfall, recharge, etc.). Both the RFR and MLR techniques identified population density as the most important variable explaining reported nitrate contamination. However, RFR has a much higher predictive power $\left(R^{2}=0.97\right)$ than a traditional linear regression model $\left(R^{2}=0.64\right)$. RFR is therefore considered a very promising technique for large-scale modelling of groundwater nitrate pollution.

In SSA, groundwater plays a fundamental, yet often little appreciated role in supporting economic development and human well-being in both urban and rural environments, as well as supporting many aquatic ecosystems. Thus, groundwater has high relevance to the development and wellbeing of SSA, if adequately assessed and sustainably exploited; however, a quantitative understanding of these issues remains poor. A review paper by Gaye and Tindimungaya highlights the main groundwater issues and problems in SSA, and the current and potential opportunities for sustainable groundwater management. Their review reveals that groundwater resources in SSA face increasing threats of pollution from urbanization, industrial development, agricultural, and mining activities, and from poor sanitation and from over-exploitation because of increasing demand to meet human and agricultural needs. Despite the prevalence of groundwater management challenges, groundwater resources in SSA are still generally under-developed, and can meet the various needs in a sustainable manner if better managed. Thus, strategies to ensure sustainable development and management of groundwater resources need to be put in place. These include the establishment of groundwater monitoring systems, understanding of the groundwater-aquatic ecosystem relationships, management of transboundary aquifers, addressing climatechange impacts on groundwater, assessing the impact of increased pumping from various types of aquifers on the sustainability of groundwater abstraction, and capacity building in groundwater management.

\section{Concluding remarks}

To address all the concerns discussed in this special issue, an integrated effort in both theory and in practice is required which includes ensuring that institutional arrangements are in place. As a common pool resource, groundwater must be valued and efficiently managed for sustainable utilization purposes, as was identified in the Cape Town water crisis study. For SSA, this means addressing the implementation of plans with the same zeal and enthusiasm given to the discussion and formulation of plans.

Acknowledgements We would like to express our gratitude to all the reviewers who greatly improved the quality of the articles published in this special issue. We also acknowledge the important contributions made by the late Phil Hobbs who passed away last year.

\section{References}

AMCOW (2012) Status report on the application of integrated approaches to water resources management in Africa. AMCOW, Abuja, Nigeria

Braune E, Xu Y (2010) The role of ground water in Sub-Saharan Africa. Ground Water 48(2):229-238

Environment Agency (2011) Groundwater protection: policy and practice (GP3), part 2: Technical framework. EA, Bristol, UK

FAO (2003) Review of world water resources by country. FAO, Rome

GW·MATE (2011) Appropriate groundwater management for SubSaharan Africa in face of demographic pressure and climatic variability. World Bank Strategic Overview Series no. 5, World Bank, Washington, DC

MacDonald AM, Bonsor HC, Dochartaigh B, Taylor RG (2012) Quantitative maps of groundwater resources in Africa. Environ Res Lett 7(2012):024009. https://doi.org/10.1088/1748-9326/7/2/ 024009

Pavelic P, Giordano M, Keraita B, Ramesh V, Rao T (Eds) (2012) Groundwater availability and use in Sub-Saharan Africa: a review of 15 countries. International Water Management Institute, Colombo, Sri Lanke

Trenberth KE, Smith L, Qian T, Dai A, Fasullo J (2007) Estimates of the global water budget and its annual cycle using observational and model data. J Hydrometeorol 8:758-769

UN (2015) The millennium development goals report 2015. UN, New York 